\title{
Effects of exercise before or after meal ingestion on fat balance and postprandial metabolism in overweight men
}

\author{
Nor M. F. Farah ${ }^{1,2}$ and Jason M. R. Gill ${ }^{1 *}$ \\ ${ }^{1}$ BHF Glasgow Cardiovascular Research Centre, Institute of Cardiovascular and Medical Sciences, College of Medical, \\ Veterinary and Life Sciences, University of Glasgow, Glasgow G12 8TA, UK \\ ${ }^{2}$ School of Rehabilitation Science, Faculty of Health Sciences, Universiti Kebangsaan Malaysia, 53200 Kuala Lumpur, \\ Malaysia \\ (Submitted 3 May 2012 - Final revision received 24 July 2012 - Accepted 28 August 2012 - First published online 26 October 2012)
}

\section{Abstract}

It is unclear how timing of exercise relative to meal ingestion influences substrate balance and metabolic responses. The present study aimed to compare the effects of exercise performed before or after breakfast on fat balance and postprandial metabolism. A total of ten sedentary overweight men (aged 28.1 (SEM 10.7) years, BMI $29 \cdot 0$ (SEM 2.8) kg/m²) underwent three trials in random order involving: (1) performing no exercise (CON), or walking for $60 \mathrm{~min}$ at $50 \%$ maximal $\mathrm{O}_{2}$ uptake either (2) before (Ex-Meal) or (3) after (Meal-Ex) consuming a standardised breakfast meal. In each trial an ad libitum lunch was provided $3.5 \mathrm{~h}$ after breakfast. Substrate utilisation was assessed by indirect calorimetry and blood was taken at regular intervals over an $8.5 \mathrm{~h}$ observation period. At the end of the observation period, fat balances in the Ex-Meal (-1043 (SEM 270) kJ) and Meal-Ex (-697 (SEM 201) kJ) trials were both significantly lower than CON (204 (SEM $165) \mathrm{kJ}$ ) and fat balance in the Ex-Meal trial was significantly lower than in the Meal-Ex trial (all $P<0 \cdot 0001$ ). Compared with the CON trial, the $8.5 \mathrm{~h}$ postprandial TAG response was only significantly lowered in the Ex-Meal trial $(-17 \%, P=0.025)$ and not in the Meal-Ex trial $(-11 \%, P=0 \cdot 20)$. Both the Ex-Meal and Meal-Ex trials showed significantly lowered insulin responses relative to the CON trial (by 19 and $24 \%$, respectively, $P<0.01$ for both). There were no differences in lunch energy intake between trials. The present findings suggest that there may be an advantage for body fat regulation and lipid metabolism in exercising before compared with after breakfast. However, further study is needed to determine whether the present findings extend over the long term under free-living conditions.

\section{Key words: Exercise: Postprandial metabolism: Fat balance: Appetite: Energy balance: Ad libitum energy intake}

Loss of body fat requires the imposition of a negative fat balance, which is achieved when fat oxidation exceeds fat intake $^{(1)}$. Exercise provides a potent means of increasing fat oxidation, both during the exercise itself and in the hours afterwards $^{(2)}$, and thus can potentially contribute to the formation of a negative fat balance. However, as exercise can also influence food intake ${ }^{(3)}$ and the metabolism of ingested food $^{(4,5)}$, it is necessary to also consider the interactions between exercise and food intake to fully evaluate the overall effects of exercise on fat balance. It is well-known that consuming a meal prior to exercise reduces fat, and increases carbohydrate oxidation during the exercise period ${ }^{(6,7)}$, whereas a post-exercise meal can attenuate the shift from carbohydrate to fat oxidation that normally follows exercise ${ }^{(8)}$. Thus, the timing of exercise relative to meal ingestion influences the pattern, and potentially the extent, of the exerciseinduced increase in fat oxidation. Studies comparing the effects of exercise before or after a single meal have reported greater total fat oxidation over observation periods of $2-8 \mathrm{~h}$ when exercise was undertaken in the fasted state ${ }^{(9,10)}$. However, as the effects of exercise on the intake and metabolism of food in subsequent meals were not evaluated in these controlled laboratory studies, the findings with respect to fat balance may not be representative of free-living situations, when ad libitum meals are ingested throughout the day. It is unclear how exercise timing around meal ingestion could affect appetitive behaviour and ad libitum food intake, and how metabolic responses to these subsequent meals can influence variations in substrate oxidation and overall fat balance throughout the post-exercise period.

An additional consideration in the temporal association of exercise and meal ingestion is its effects on postprandial TAG and insulin responses. A large body of evidence has shown that exercise is effective in ameliorating the unfavourable exaggerations in postprandial lipaemia and insulinaemia ${ }^{(11)}$, which may have implications for the prevention of

Abbreviations: CON, control; Ex-Meal, exercise before breakfast meal; LPL, lipoprotein lipase; Meal-Ex, exercise after breakfast meal.

*Corresponding author: Dr J. M. R. Gill, fax +44 141 3302522, email jason.gill@glasgow.ac.uk 
atherogenesis $^{(12,13)}$. In most of these studies, exercise performed $4-18 \mathrm{~h}$ prior to a high-fat meal effectively reduced postprandial TAG and insulin responses ${ }^{(5,14-17)}$. Exercise performed immediately prior to meal ingestion has also been shown to reduce postprandial TAG concentrations ${ }^{(18,19)}$; however, in studies that evaluated the effects of post-meal exercise on postprandial lipaemia, findings have been mixed, with some studies reporting a decrease in postprandial $\mathrm{TAG}^{(18,20-22)}$ and others reporting no change ${ }^{(19,23)}$. However, the findings of these reports are limited by the absence of subsequent meals in the post-exercise period, which can make an impact on the magnitude and duration of the exercise-induced metabolic responses; it is clear that post-exercise energy and carbohydrate intakes substantially modify the effects of exercise on insulin sensitivity and lipoprotein metabolism $^{(14,24,25)}$. Furthermore, the amount of food consumed in meals later in the day and, therefore, the metabolic responses of these meals, may be influenced by exercise timing relative to breakfast. Thus, it is not known how exercise timing relative to breakfast ingestion with subsequent ad libitum food ingestion has an impact on day-long postprandial lipid and insulin metabolism.

The purpose of the present study was therefore to investigate the effects of a single session of moderate-intensity exercise, undertaken either before or after a standardised breakfast meal, on postprandial substrate, lipid and insulin/glucose metabolism, as well as on appetite responses and subsequent energy intake in overweight men. We hypothesised that exercise performed before breakfast would result in a lower overall fat balance and a lower postprandial TAG response than a similar exercise session performed after breakfast.

\section{Experimental methods}

\section{Participants}

A total of fifteen overweight (BMI $>25 \mathrm{~kg} / \mathrm{m}^{2}$ ) men, with low levels of habitual physical activity (less than $1 \mathrm{~h}$ per week of moderate-to-vigorous physical activity, assessed by the International Physical Activity Questionnaire), were recruited through advertisements. Of these, two participants dropped out after initial screening and a further three participants dropped out after completion of preliminary tests and before undertaking any of the main experimental trials. Thus, ten participants completed all three experimental trials and were included in the data analysis. The age, body mass, BMI, waist circumference, predicted maximum $\mathrm{O}_{2}$ uptake $\left(\mathrm{VO}_{2 \text { max }}\right)$ and total cholesterol concentrations of these ten participants were as follows: $28 \cdot 1$ (SD 10.7) years, $92 \cdot 2$ (SD 11.7$) \mathrm{kg}, \quad 29 \cdot 0 \quad(\mathrm{SD} 2 \cdot 8) \mathrm{kg} / \mathrm{m}^{2}, \quad 93 \cdot 2 \quad(\mathrm{SD} \quad 8 \cdot 6) \mathrm{cm}, \quad 39 \cdot 1$ (SD 5.4) $\mathrm{ml} / \mathrm{kg}$ per $\mathrm{min}$ and 4.23 (SD 1.04 ) $\mathrm{mmol} / \mathrm{l}$, respectively. Participants were non-smokers, with no known history of CVD or diabetes, and were not consuming any type of specialised diet (e.g. vegetarian, high protein or weight reducing) or taking any medications thought to interfere with energy substrate metabolism and appetite. The present study was conducted according to the guidelines laid down in the Declaration of Helsinki and all procedures involving human subjects were approved by the Faculty of Biomedical and Life Sciences Ethics Committee at the University of Glasgow, UK. Each participant gave written informed consent prior to participation.

\section{Dietary restraint}

Dietary restraint was measured by the restraint scale on the Three Factor Eating Questionnaire ${ }^{(26)}$ and Dutch Eating Behaviour Questionnaire ${ }^{(27)}$. The dietary restraint scores were $6 \cdot 1(\operatorname{sem} 3 \cdot 0)$ and $2 \cdot 4$ (SEM 0.4 ), respectively. None of the participants was classified as a restrained eater.

\section{Study design}

Following preliminary tests (described later), each participant completed three $8.5 \mathrm{~h}$ experimental trials in randomised order, with an interval of 1-2 weeks between trials: exercise before a breakfast meal (Ex-Meal), exercise after a breakfast meal (Meal-Ex) and control (CON). Randomisation was undertaken in blocks of six (to reflect the six possible orders of testing) by drawing a folded piece of paper, numbered from one to six, from an envelope, with each number corresponding to a different testing order. The experimental protocol is shown in Fig. 1. For $2 \mathrm{~d}$ prior to their first trial, participants weighed and recorded all their food and drink intake and were instructed to replicate this diet for the $2 \mathrm{~d}$ preceding their subsequent experimental trials. Diets were analysed using a computerised version of a food composition table (CompEat Pro; Nutrition Systems). They were also asked to refrain from alcohol and planned exercise, and maintain their usual day-to-day activities during this recording period.

\section{Preliminary tests}

Before undertaking the main experimental trials, participants undertook a four-stage incremental sub-maximal treadmill walk test to estimate $\dot{\mathrm{VO}}_{2}$ max and calculate the speed and gradient required to elicit the intensity of $50 \% \dot{\mathrm{VO}}_{2}$ max for the exercise intervention. Before the main trials, each participant was also asked about food they disliked and whether they had any food allergies. This information was used to ensure that foods provided in the ad libitum buffet were suitable and acceptable for their consumption.

\section{Main trials}

Exercise before breakfast meal. Participants arrived at the metabolic suite at 08.00 hours following a $12 \mathrm{~h}$ overnight fast. Following $10 \mathrm{~min}$ supine rest on a couch, a $25 \mathrm{~min}$ fasting expired sample was collected using a ventilated hood system (Oxycon Pro, Jaeger GmbH) to estimate RMR and substrate utilisation using indirect calorimetry ${ }^{(28)}$. A cannula was then introduced into an antecubital vein for repeated blood sampling. Participants were asked to rate their fasting appetite sensations using $100 \mathrm{~mm}$ visual analogue scales ${ }^{(29)}$ (see later for details) and a fasting blood sample was taken immediately before the commencement of the exercise session. The exercise session 


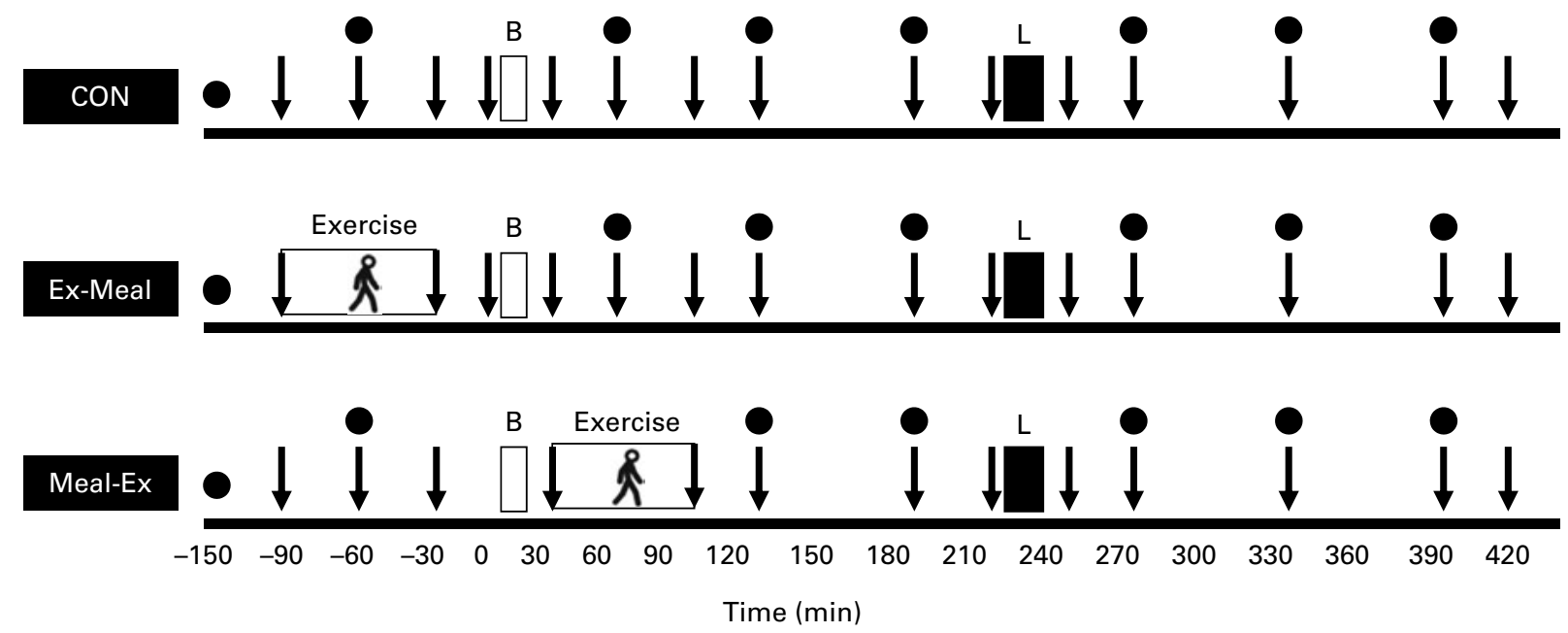

Fig. 1. Study design. Participants completed three trials: control (CON), exercise before breakfast meal (Ex-Meal) and exercise after breakfast meal (Meal-Ex). B, test breakfast; L, buffet lunch; walking man denotes $1 \mathrm{~h}$ exercise session; $\bullet$, expired air measurements; $\downarrow$, blood samples and appetite questionnaires.

began at 09.00 hours ( -90 min in Fig. 1): all participants completed a 60 min treadmill walk at $50 \%$ of $\dot{\mathrm{V}} \mathrm{O}_{2 \text { max }}$. Expired air samples were collected at $15 \mathrm{~min}$ intervals during the walk and for $15 \mathrm{~min}$ in the recovery period using Douglas bags for the determination of $\mathrm{O}_{2}$ uptake and $\mathrm{CO}_{2}$ production. Fat and carbohydrate oxidation during exercise was estimated using indirect calorimetry ${ }^{(28)}$. Heart rate and ratings of perceived exertion were recorded at every $15 \mathrm{~min}$ during the walk. Blood samples were collected at $30 \mathrm{~min}$ during the walk and immediately after the walk ended. Participants also recorded their appetite sensation ratings at the end of the walk. At 10.30 hours ( $0 \mathrm{~min}$ in Fig. 1), i.e. $30 \mathrm{~min}$ after completion of the exercise session, participants were provided with a test breakfast, as described later. On completion of the meal, participants underwent a $7 \mathrm{~h}$ postprandial observation period, during which blood samples and visual analogue scales ratings were collected at 30,60,90,120,180, 210, 240, 270, 330, 390 and $420 \mathrm{~min}$. Subsequent expired air measurements were made using the ventilated hood system for $15 \mathrm{~min}$ at 60,120 , 180, 270, 330 and $390 \mathrm{~min}$. Ad libitum lunch, as described later, was served at 210 (14.00 hours) min.

Exercise after breakfast meal trial. This trial was identical to the Ex-Meal trial, except that participants rested for $1 \mathrm{~h}$ from 09.00 to 10.00 hours, and performed the $1 \mathrm{~h}$ exercise session at 11.00 hours ( $30 \mathrm{~min}$ in Fig. 1), i.e. $30 \mathrm{~min}$ after the test breakfast was provided.

Control trial. This trial was identical to both exercise trials, except that participants undertook no exercise and remained rested during the periods (i.e. $09.00-10.00$ and $11.00-12.00$ hours), which corresponded to the exercise session in the Ex-Meal and Meal-Ex trials, respectively.

\section{Test breakfast}

Participants were provided with a standardised breakfast, which provided $20.9 \mathrm{~kJ}(5 \mathrm{kcal})$ of energy per kg body mass. This size of meal was chosen to reflect a typical breakfast energy intake. The meal comprised a plain bagel $(0.44 \mathrm{~g} / \mathrm{kg}$, New York
Bakery Company), polyunsaturated fat margarine $(0.05 \mathrm{~g} / \mathrm{kg}$, Flora original; Unilever) and a meal-replacement drink ( $0.56 \mathrm{~g} /$ $\mathrm{kg}$, Strawberry-flavoured Complan, Complan Foods Limited) made with whole milk $(1.79 \mathrm{ml} / \mathrm{kg})$, and provided $49 \%$ of energy from carbohydrate, $37 \%$ from fat and $14 \%$ from protein to match the typical British daily macronutrient intake ${ }^{(30)}$. Participants were asked to consume the meal within $10 \mathrm{~min}$.

\section{Ad libitum energy intake}

An ad libitum buffet lunch, containing spaghetti Bolognese (700 g provided from frozen 'ready-meals', Wm Morrison Supermarkets), salad (80 g salad leaves mix, Wm Morrison Supermarkets), vinaigrette dressing (100 g, Wm Morrison Supermarkets), microwaved fries (200 g, Micro Chips, McCain Foods (GB) Limited), potato crisps (150 g, Red Thai Chilli Crisps, Wm Morrison Supermarkets), fruit (150 g Clementine oranges, $120 \mathrm{~g}$ banana), yogurt (300 g Strawberry 'fat-free' yogurt, Onken Limited) and chocolate (60 g Choc Flakes, Marks and Spencers) (approximately $10500 \mathrm{~kJ}$ of energy available), was provided $3.5 \mathrm{~h}$ after breakfast. Food was presented in excess of expected consumption and participants were told to eat until they felt comfortably full. Participants were given $20 \mathrm{~min}$ to consume the ad libitum meal. They were not informed that consumption was being measured (but were informed of this on the completion of the study), and they consumed the meal without experimenters being present, to minimise potential alterations to usual feeding behaviour ${ }^{(31)}$. All foods were covertly weighed before they were made available to the subjects and reweighed again after meal ingestion to quantify food intake. Energy, protein, fat and carbohydrate intakes were calculated using manufacturers' values and food composition tables when manufacturers' labels were not available. Participants were not provided with water during the meal, but ad libitum access to water was made available throughout the day before and after the completion of the meal. From the energy intake at lunch, relative energy intake 
(i.e. post-exercise energy intake corrected for the net energy cost of exercise) was calculated.

\section{Subjective appetite ratings}

Subjective assessment of appetite was made using visual analogue scales adapted from Flint et al. ${ }^{(29)}$. Each scale consisted of a $100 \mathrm{~mm}$ horizontal line anchored at either end with statements 'not at all' and 'extremely'. The questionnaire that was used consisted of five visual analogue scales to rate 'hunger', 'fullness', 'satisfaction', 'desire to eat' and 'prospective food consumption'.

\section{Blood analysis}

Venous blood samples were collected into pre-cooled potassium EDTA tubes and placed on ice before centrifugation to separate plasma within $15 \mathrm{~min}$ of collection. Plasma was stored at $-80^{\circ} \mathrm{C}$ until analysis. TAG and glucose concentrations were determined by an enzymatic colorimetric method using a commercially available kit (Horiba ABX). Insulin concentration was determined using a commercially available ELISA (Mercodia). All samples for each subject were analysed in duplicate and in a single analyser run. $\mathrm{CV}$ for the TAG, glucose and insulin assays were $<2,<3$ and $<5 \%$, respectively.

\section{Validity and reliability of the Oxycon Pro ventilated hood system}

Prior to commencement of the present study, the validity of the Oxycon Pro ventilated hood device system was assessed by comparing values for resting $\mathrm{O}_{2}$ uptake $\left(\mathrm{VO}_{2}\right)$ and $\mathrm{CO}_{2}$ production $\left(\mathrm{VCO}_{2}\right)$ obtained using the Oxycon Pro with values obtained using Douglas bag expired air collections in eleven volunteers in the fasted state. Each volunteer underwent consecutive collections of expired air using the Oxycon Pro ventilated hood and into Douglas bags via a mouthpiece in random order. $\mathrm{VO}_{2}$ and $\mathrm{VCO}_{2}$ values were $0 \cdot 21$ (SD 0.05) and 0.17 (SD 0.06) litres/min for the Douglas bag measurements and 0.20 (SD 0.06) and $0.16(0.05)$ litres $/ \mathrm{min}$ for the Oxycon Pro measurements, respectively. The mean percentage difference between the Douglas bag and Oxycon Pro measurements was -4.4 (SD 8.3 ) $\%$ for $\mathrm{VO}_{2}$ and -7.5 (SD 8.5 ) $\%$ for $\mathrm{VCO}_{2}$, and the Pearson correlation coefficients between the measurement techniques were 0.964 $(P<0.0005)$ for $\mathrm{VO}_{2}$ and $0.972(P<0.0005)$ for $\mathrm{VCO}_{2}$.

The reliability of the Oxycon Pro system was determined by comparing resting $\mathrm{VO}_{2}$ and $\mathrm{VCO}_{2}$ measurements made in the fasted state in ten volunteers on two occasions with an interval of 1-2 weeks (these were different volunteers from those recruited to determine the system's validity). Volunteers refrained from exercise and replicated their dietary intakes for the $2 \mathrm{~d}$ prior to each measurement. Mean $\mathrm{VO}_{2}$ and $\mathrm{VCO}_{2}$ values were 0.27 (SD 0.02) and 0.22 (SD 0.02) litres/min for the first measurement and 0.27 (SD 0.03 ) and 0.22 (SD 0.03) litres/min for the second measurement, respectively.

The mean difference between measurements was 0.6
(SD $6 \cdot 1$ ) $\%$ for $\mathrm{VO}_{2}$ and $0 \cdot 7$ (SD $4 \cdot 6$ ) $\%$ for $\mathrm{VCO}_{2}$, and the Pearson correlation coefficients between measurements were 0.913 $(P<0.0005)$ for $\mathrm{VO}_{2}$ and $0.943(P<0.0005)$ for $\mathrm{VCO}_{2}$.

\section{Power calculation}

We primarily based the present sample size calculation on the number of participants needed to detect a difference in overall fat balance between the Ex-Meal and Meal-Ex trials. Our previous data had shown that the within-participant standard deviation for differences in fat balance between conditions of low and high energy turnover at the end of a similar postprandial observation period was $0.31 \mathrm{MJ}^{(4)}$. We assumed that the within-participant standard deviation for differences between trials in the present investigation would be similar. Based on this, we calculated that ten participants would be sufficient to detect a $0.31 \mathrm{MJ}$ difference in fat balance between trials, with $80 \%$ power. In addition, based on our previous observations that the within-participant standard deviations for postprandial TAG and insulin responses were $10 \cdot 1$ and $22.9 \%$, respectively ${ }^{(32)}$, the chosen sample size of ten participants would also enable detection of differences between trials of approximately $10 \%$ in the TAG response and approximately $23 \%$ in the insulin response with the same power.

\section{Statistical analysis}

Statistical analyses were performed using Statistica (version 6.0, StatSoft, Inc.) and SPSS (version 13.0, SPSS, Inc.). Data were tested for normality prior to analysis and no data required transformation. Time-averaged AUC (i.e. AUC divided by time to provide a mean value for the observation interval) for the 'before breakfast' (i.e. -90 to $0 \mathrm{~min}$ ), 'breakfast to lunch' (0-210 min), 'after lunch' (210-240 min) and the total $8.5 \mathrm{~h}$ observation period $(-90$ to $420 \mathrm{~min}$ ) were calculated as summary measures of the postprandial responses. Cumulative energy and energy substrate balances were calculated by summing the AUC between individual time points throughout each experimental trial. One-way repeated-measures ANOVA were used to compare fasting values, 8.5 h AUC, energy intakes and energy expenditures across the three trials. Two-way repeated-measures ANOVA (trial $\times$ time) were used to compare changes over time and across the three trials. Post hoc Tukey tests were used to identify where differences lay. Data are presented as mean values and their standard errors, unless otherwise stated. Statistical significance was accepted at $P<0.05$. All $P$ values are reported for two-sided tests.

\section{Results}

\section{Responses during the treadmill walk}

The treadmill speed and gradient for both exercise sessions (Ex-Meal and Meal-Ex) were identical within each participant. Participants walked for $60 \mathrm{~min}$ at an average speed of 5.5 (SEm $0 \cdot 1) \mathrm{km} / \mathrm{h}$ on a gradient of $4.3($ SEM $0 \cdot 8) \%$. All exercise sessions were completed without difficulty and participants 
rated the exercise as 'light' on the Borg scale of 6-20 in both the Ex-Meal (10.4 (SEm 0.6)) and Meal-Ex (10.5 (sEM 0.6)) trials. Mean $\mathrm{O}_{2}$ uptakes and heart rates over the course of the exercise sessions were 20.1 (SEM 0.8) $\mathrm{ml} / \mathrm{kg}$ per min and 127 (SEM 4) beats/min, respectively, in the Ex-Meal trial, and 19.5 (SEM $0 \cdot 8) \mathrm{ml} / \mathrm{kg}$ per min and 129 (SEM 4) beats/min, respectively, in the Meal-Ex trial. Values did not differ significantly between trials.

\section{Metabolic responses in the fasted state}

RMR (CON: $5 \cdot 31$ (SEM 0.14) kJ/min; Ex-Meal: 5.25 (sEM $0 \cdot 19) \mathrm{kJ} / \mathrm{min}$ and Meal-Ex: $5.35(\operatorname{sem} 21) \mathrm{kJ} / \mathrm{min}$ ), rate of fat oxidation (CON: 0.084 (SEM 0.005) g/min; Ex-Meal: 0.075 (SEm 0.010) $\mathrm{g} / \mathrm{min}$ and Meal-Ex: 0.090 (SEM 0.009) $\mathrm{g} / \mathrm{min}$ ) and rate of carbohydrate oxidation (CON: 0.132 (SEM 0.014) g/min; Ex-Meal: 0.150 (SEM 0.019) g/min and Meal-Ex: $0 \cdot 120(\operatorname{sem} 0 \cdot 019) \mathrm{g} / \mathrm{min}$ ) measured in the fasted state at 08.00 hours in all trials did not differ significantly between trials. Similarly, there were no significant differences between trials in fasting plasma TAG (CON: 1.01 (sem 0.09) mmol/1; Ex-Meal: 0.97 (sem 0.08) mmol/l and Meal-Ex: 0.99 (sem 0.10) mmol/1), insulin (CON: 7.05 (SEM 0.82) mU/1; Ex-Meal: 6.16 (sEM $0.95) \mathrm{mU} / 1$ and Meal-Ex: $6.97(\operatorname{sem} 1.07) \mathrm{mU} / \mathrm{l})(1 \mathrm{mU} / \mathrm{l}=6.945$ pmol/1) or glucose (CON: $5 \cdot 17(\operatorname{sem~} 0 \cdot 11) \mathrm{mmol} / \mathrm{l}$; Ex-Meal: $5 \cdot 11(\operatorname{sem} 0 \cdot 16) \mathrm{mmol} / \mathrm{l}$ and Meal-Ex: $5 \cdot 32(\operatorname{sem} 0 \cdot 14) \mathrm{mmol} / \mathrm{l})$ concentrations.

\section{Metabolic responses during exercise}

Summary data for energy expenditure and substrate utilisation during exercise are presented in Table 1 . The total net exercise energy expenditure did not differ significantly between exercise trials $(P=0.657)$. The net amount of fat oxidised during exercise was $33 \%$ greater in the Ex-Meal compared with the Meal-Ex trial $(P=0.005)$. Reciprocally, the net amount of carbohydrate oxidised was $18 \%$ lower in the Ex-Meal trial compared with the Meal-Ex trial $(P=0.003)$.

\section{Postprandial energy and substrate utilisation}

Postprandial energy expenditure and substrate utilisation are presented in Table 1. Total energy expenditure over the $8.5 \mathrm{~h}$ observation period was greater in both the Ex-Meal and Meal-Ex trials, compared with the CON trial $(P<0.001$ for both). Total fat oxidation over this period was 53 and $43 \%$ greater in the Ex-Meal and Meal-Ex trials, respectively, compared with the CON trial $(P<0.001$ for both). Similarly, total carbohydrate oxidation was $55 \%$ greater in the Ex-Meal trial and $65 \%$ greater in the Meal-Ex trial than the CON trial $(P<0.001$ for both). None of these values differed between the Ex-Meal and Meal-Ex trials. However, when the net energy expenditure and substrate utilisation during exercise were subtracted from the total values, there were no significant differences observed in energy expenditure and substrate utilisation over the observation period between trials. Thus, differences in energy and substrate utilisation between trials over the $8.5 \mathrm{~h}$ observation period could be entirely accounted for by energy and substrate utilisation during the exercise session itself.

\section{Ad libitum energy intake and relative energy intake}

There were no significant differences in energy intake in the ad libitum lunch between trials (CON: 5212 (SEM 393) kJ; Ex-Meal: 5041 (sem 376) kJ and Meal-Ex: 5179 (sem $443) \mathrm{kJ}$ ). Similarly, intake of carbohydrate (CON: 2780 (sEm 222) kJ; Ex-Meal: 2696 (sEm 196) kJ and Meal-Ex: 2725 (sEm 226) kJ), fat (CON: 1396 (sEm 38) kJ; Ex-Meal: 1300 (sEm 146) $\mathrm{kJ}$ and Meal-Ex: 1413 (SEM 201) kJ) and protein (CON: 1032 (sem 75) kJ; Ex-Meal: 1041 (sem 67) kJ and Meal-Ex: 1037 (sEm 63) kJ) did not differ significantly between trials. However, relative energy intake (i.e. lunch energy intake minus net exercise energy expenditure) was significantly lower in the Ex-Meal (3231 (sEm 389) kJ) and Meal-Ex (3386 $($ SEM 426$) \mathrm{kJ}$ ) trials, compared with the CON trial $(5212$ (SEM 393) kJ, $P<0.001$ for both).

Table 1. Energy expenditure and substrate utilisation during exercise (net values) for the total $8.5 \mathrm{~h}$ observation period (including exercise expenditure) and for the total $8.5 \mathrm{~h}$ observation period (excluding net exercise expenditure) (Mean values with their standard errors, $n$ 10)

\begin{tabular}{|c|c|c|c|c|c|c|}
\hline & \multicolumn{2}{|c|}{ CON } & \multicolumn{2}{|c|}{ Ex-Meal } & \multicolumn{2}{|c|}{ Meal-Ex } \\
\hline & Mean & SEM & Mean & SEM & Mean & SEM \\
\hline \multicolumn{7}{|l|}{ During exercise } \\
\hline Energy expenditure (kJ) & & & 1810 & 100 & 1793 & 100 \\
\hline Fat oxidation $(\mathrm{g})$ & & & $23 \cdot 0 \dagger \dagger$ & $1 \cdot 3$ & $17 \cdot 3$ & 1.3 \\
\hline Carbohydrate oxidation (g) & & & $59 \cdot 2+\dagger$ & $6 \cdot 7$ & 72.4 & 6.5 \\
\hline \multicolumn{7}{|c|}{ Total $8.5 \mathrm{~h}$ observation periods (including exercise) } \\
\hline Energy expenditure (kJ) & 3273 & 109 & $5045^{\star \star}$ & 167 & $4983^{\star *}$ & 180 \\
\hline Fat oxidation (g) & $49 \cdot 6$ & $2 \cdot 2$ & $76 \cdot 1^{\star \star}$ & $4 \cdot 6$ & $71 \cdot 1^{\star *}$ & $2 \cdot 8$ \\
\hline Carbohydrate oxidation (g) & $87 \cdot 0$ & $5 \cdot 3$ & $134 \cdot 9^{\star \star}$ & $12 \cdot 7$ & $143 \cdot 9^{\star \star}$ & 8.0 \\
\hline \multicolumn{7}{|c|}{ Total $8.5 \mathrm{~h}$ observation periods (excluding exercise) } \\
\hline Energy expenditure $(\mathrm{kJ})$ & 3273 & 109 & 3231 & 100 & 3189 & 96 \\
\hline Fat oxidation $(\mathrm{g})$ & $49 \cdot 6$ & $2 \cdot 2$ & 53.0 & 3.8 & $53 \cdot 6$ & 2.5 \\
\hline Carbohydrate oxidation (g) & $87 \cdot 0$ & $5 \cdot 3$ & $75 \cdot 8$ & 8.4 & $72 \cdot 4$ & 5.5 \\
\hline
\end{tabular}

CON, control; Ex-Meal, exercise before breakfast; Meal-Ex, exercise after breakfast.

${ }^{* \star}$ Mean value was significantly different from $\operatorname{CON}(P<0.01)$

†† Mean value was significantly different from Meal-Ex $(P<0.01)$ 


\section{Subjective appetite responses}

Summary measures of appetite responses for the 'before breakfast', 'breakfast to lunch' and 'after lunch' observation periods are shown in Table 2. There was a main effect of time period $(P<0.001)$ for each appetite perception assessed (hunger, desire to eat, prospective food consumption, fullness and satisfaction). In other words, appetite sensations varied throughout the day. For hunger, a significant trial $\times$ timeperiod interaction $(P=0.035)$ was observed, but post boc Tukey tests did not reveal any differences between trials for individual time periods. No other differences between trials were observed for any of the other appetite variables.

\section{Cumulative energy and substrate balances}

Cumulative energy, fat and carbohydrate balances, measured throughout the $8.5 \mathrm{~h}$ observation period for each trial, are shown in Fig. 2. Energy balance was significantly lower in the Ex-Meal trial than in the CON trial throughout the observation period from the $-60 \mathrm{~min}$ time point onwards, and was significantly lower in the Meal-Ex trial than in the CON trial from the $60 \mathrm{~min}$ time point onwards. At the end of the observation period, energy balances in the Ex-Meal (1630 (sEm 378$) \mathrm{kJ}$, relative to the start of the trial) and the Meal-Ex (1768 (sEm 358) kJ) trials did not differ from each other, but were both significantly lower than energy balance in the CON trial $(3743$ (sem 323) kJ; $P<0.0001$ for both). The same trend was observed for postprandial carbohydrate balance. At the end of the observation period, carbohydrate balances were significantly lower in the Ex-Meal (1341 (sEm 199) kJ) and Meal-Ex (1253 (sem 190) kJ) trials compared with the CON trial (2301 (sem 176) kJ, $P<0.0001$ for both), with no differences observed between the exercise trials. However, a different trend was evident for fat balance, with fat balance being significantly lower in the Ex-Meal than in both the Meal-Ex and CON trials throughout the observation period from the $-60 \mathrm{~min}$ time point onwards. Fat balance was significantly lower in the Meal-EX than in the CON trial from the $60 \mathrm{~min}$ time point onwards. At the end of the observation period, fat balances in the Ex-Meal ( -1043 (SEm 270) kJ) and Meal-Ex ( 697 (SEM 201) kJ) trials were both significantly lower than in the CON trial $(204($ SEM 165$) \mathrm{kJ})$, and fat balance in the Ex-Meal trial was significantly lower than in the Meal-Ex (all $P<0.0001$ ) trial.

\section{Postprandial metabolic responses}

Fig. 3 illustrates the postprandial responses for TAG, insulin and glucose over the $8.5 \mathrm{~h}$ observation period, and summary responses are shown in Table 3 . The TAG responses in the 'before breakfast' and 'breakfast to lunch' observation periods did not differ significantly between trials, but TAG responses in the 'after lunch' period were 19 and 17\% lower than the CON trial in the Ex-Meal and the Meal-Ex trials, respectively ( $P<0.01$ for both). However, over the total $8.5 \mathrm{~h}$ observation period, only the Ex-Meal trial $(-17 \%, P=0.025)$ and not the Meal-Ex trial $(-11 \%, P=0 \cdot 20)$ lowered the TAG response compared with the CON trial. In contrast to the TAG responses, both the Ex-Meal $(-26 \%, P=0.05)$ and Meal-Ex $(-40 \%, P=0.001)$ trials significantly lowered insulin responses compared with the CON trial in the 'breakfast to lunch', but not in the 'after lunch', period. Over the total $8.5 \mathrm{~h}$ observation period, both the Ex-Meal and Meal-Ex trials significantly lowered insulin responses relative to the CON trial (by 19 and 24\%, respectively; $P<0.01$ for both). There were no significant differences in glucose responses between trials.

Table 2. Time-averaged AUC for subjective ratings of appetite for the before breakfast, breakfast-to-lunch and after lunch observation periods

(Mean values with their standard errors, $n$ 10)

\begin{tabular}{|c|c|c|c|c|c|c|}
\hline \multirow{2}{*}{ Time interval ... } & \multicolumn{2}{|c|}{$\begin{array}{l}\text { Before breakfast } \\
(-90 \text { to } 0 \mathrm{~min})\end{array}$} & \multicolumn{2}{|c|}{$\begin{array}{l}\text { Breakfast to lunch } \\
(0-210 \mathrm{~min})\end{array}$} & \multicolumn{2}{|c|}{$\begin{array}{c}\text { After lunch } \\
(210-420 \mathrm{~min})\end{array}$} \\
\hline & Mean & SEM & Mean & SEM & Mean & SEM \\
\hline \multicolumn{7}{|l|}{ Hunger } \\
\hline CON & 59.7 & $7 \cdot 0$ & 51.9 & $5 \cdot 7$ & 34.8 & $4 \cdot 6$ \\
\hline Ex-Meal & $52 \cdot 3$ & $7 \cdot 4$ & $61 \cdot 7$ & $5 \cdot 0$ & $30 \cdot 6$ & 3.9 \\
\hline Meal-Ex & 57.7 & 8.6 & $49 \cdot 6$ & $5 \cdot 3$ & 29.5 & $3 \cdot 3$ \\
\hline \multicolumn{7}{|l|}{ Desire to eat } \\
\hline CON & 59.9 & $8 \cdot 1$ & 57.5 & $5 \cdot 6$ & $27 \cdot 7$ & 2.8 \\
\hline Ex-Meal & 59.1 & $7 \cdot 4$ & $60 \cdot 6$ & 5.5 & 28.9 & 3.4 \\
\hline Meal-Ex & $56 \cdot 6$ & 8.4 & $50 \cdot 0$ & $5 \cdot 3$ & 28.7 & $2 \cdot 8$ \\
\hline \multicolumn{7}{|c|}{ Prospective food consumption } \\
\hline CON & $64 \cdot 4$ & $7 \cdot 0$ & $58 \cdot 8$ & $5 \cdot 6$ & $37 \cdot 3$ & 3.5 \\
\hline Ex-Meal & 66.5 & $5 \cdot 6$ & 65.9 & $4 \cdot 3$ & 34.6 & 3.4 \\
\hline Meal-Ex & $61 \cdot 8$ & $7 \cdot 0$ & 56.5 & $4 \cdot 7$ & $35 \cdot 1$ & 3.0 \\
\hline \multicolumn{7}{|l|}{ Fullness } \\
\hline CON & 28.4 & $7 \cdot 3$ & 38.9 & $4 \cdot 7$ & 81.8 & 3.3 \\
\hline Ex-Meal & $26 \cdot 4$ & $5 \cdot 8$ & $33 \cdot 6$ & 4.3 & $81 \cdot 2$ & 3.9 \\
\hline Meal-Ex & $26 \cdot 3$ & $5 \cdot 1$ & $40 \cdot 2$ & 4.0 & 81.8 & $3 \cdot 3$ \\
\hline \multicolumn{7}{|l|}{ Satisfaction } \\
\hline CON & 31.4 & $7 \cdot 3$ & $40 \cdot 2$ & $5 \cdot 0$ & 78.7 & 3.4 \\
\hline Ex-Meal & 30.0 & $5 \cdot 6$ & 34.2 & $4 \cdot 1$ & 80.5 & 3.5 \\
\hline Meal-Ex & 29.2 & 4.9 & 43.0 & 3.9 & 81.0 & 3.0 \\
\hline
\end{tabular}

CON, control; Ex-Meal, exercise before breakfast; Meal-Ex, exercise after breakfast. 

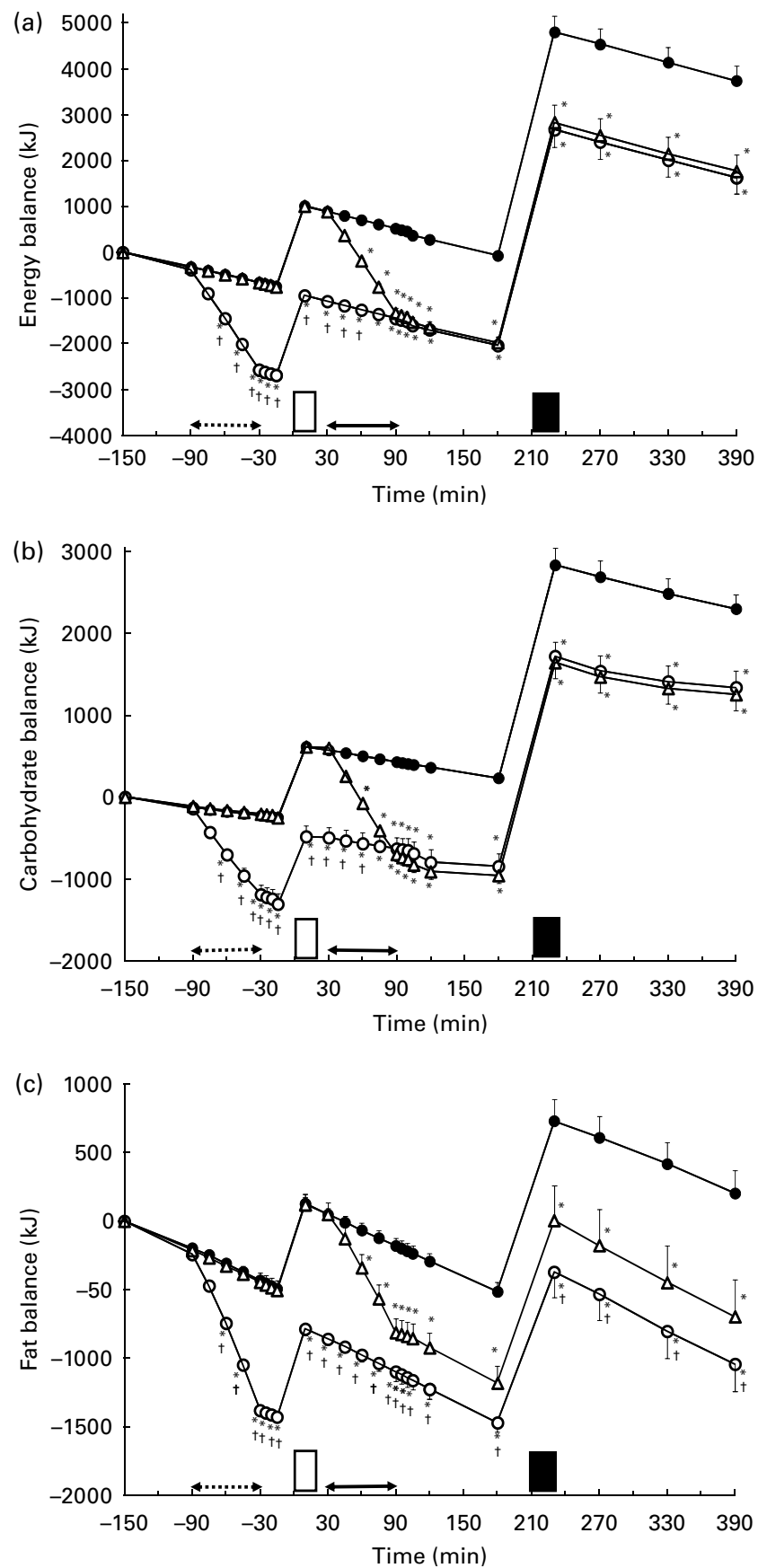

Fig. 2. (a) Cumulative energy, (b) carbohydrate and (c) fat balances over the $8.5 \mathrm{~h}$ observation period. Values are means, with their standard errors represented by vertical bars. $\square$, Test breakfast; $\mathbf{\square}$, buffet lunch; ...., exercise in the Ex-Meal (exercise before breakfast meal, -0 ) trial; $\longrightarrow$, exercise in the Meal-Ex (exercise after breakfast meal, $-\downarrow)$ ) trial. * Mean value was significantly different from $\operatorname{CON}(-)(P<0.001)$. † Mean value was significantly different from Meal-Ex $(P<0.001)$.

\section{Discussion}

The aim of the present study was to determine the effects of exercise undertaken before or after a meal on postprandial substrate, lipid and insulin/glucose metabolism, appetite responses and ad libitum feeding over the course of several hours. The main findings were that exercise undertaken both before and after a standardised breakfast meal led to lower energy, fat and carbohydrate balances at the end of an $8.5 \mathrm{~h}$ observation period, which included an ad libitum lunch, compared with a no exercise CON trial. Both exercise trials also significantly reduced the postprandial insulin response over the total $8.5 \mathrm{~h}$ observation period and the postprandial TAG response in the 'breakfast to lunch' period. However, fat balance was approximately $350 \mathrm{~kJ}$ lower
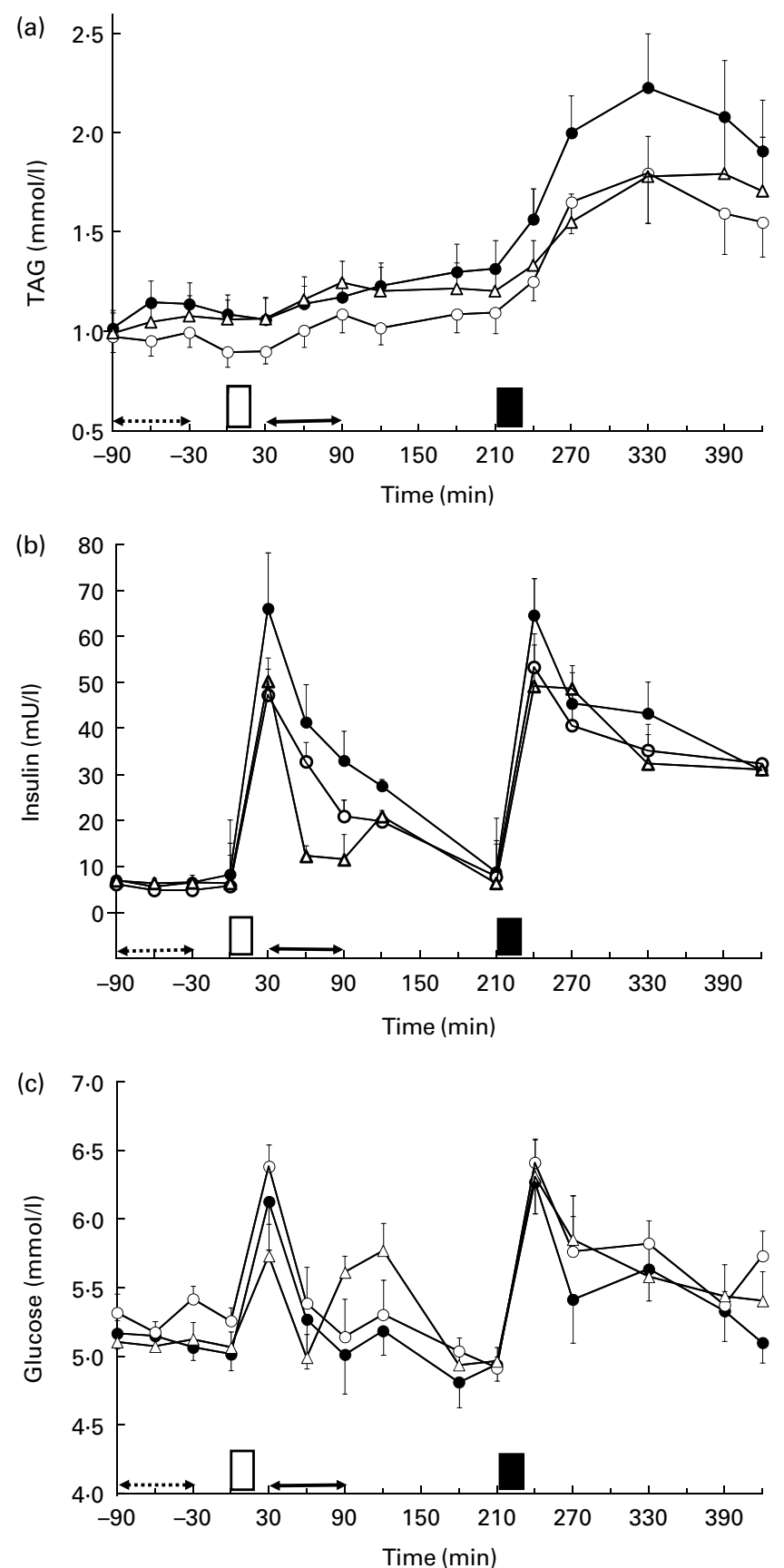

Fig. 3. (a) TAG, (b) insulin and (c) glucose responses over the $8.5 \mathrm{~h}$ observation period. Values are means, with their standard errors represented by the vertical bars. $\square$, Test breakfast; $\mathbf{\square}$, buffet lunch; ...., exercise in the Ex-Meal (exercise before breakfast meal, -0 ) trial; $\longleftrightarrow$, exercise in the Meal-Ex (exercise after breakfast meal, $-\downarrow$ ) trial. $-\bullet$, Control. For insulin, $1 \mathrm{mU} / \mathrm{l}=6.945 \mathrm{pmol} / \mathrm{l}$. 
Table 3. Time-averaged AUC for TAG, insulin and glucose for the before breakfast, breakfast-to-lunch, after lunch and total observation periods

(Mean values with their standard errors, $n$ 10)

\begin{tabular}{|c|c|c|c|c|c|c|c|c|}
\hline \multirow{2}{*}{ Time interval ... } & \multicolumn{2}{|c|}{$\begin{array}{l}\text { Before breakfast } \\
\text { ( }-90 \text { to } 0 \mathrm{~min})\end{array}$} & \multicolumn{2}{|c|}{$\begin{array}{l}\text { Breakfast to lunch } \\
\qquad(0-210 \mathrm{~min})\end{array}$} & \multicolumn{2}{|c|}{$\begin{array}{c}\text { After lunch } \\
(210-420 \mathrm{~min})\end{array}$} & \multicolumn{2}{|c|}{$\begin{array}{c}\text { Total observation } \\
\text { period } \\
\text { ( }-90 \text { to } 240 \mathrm{~min})\end{array}$} \\
\hline & Mean & SEM & Mean & SEM & Mean & SEM & Mean & SEM \\
\hline \multicolumn{9}{|l|}{ TAG (mmol/l) } \\
\hline $\mathrm{CON}$ & $1 \cdot 11$ & $0 \cdot 10$ & $1 \cdot 19$ & 0.11 & 1.96 & 0.22 & 1.50 & 0.15 \\
\hline Ex-Meal & 0.96 & 0.07 & 1.02 & 0.07 & $1.58^{\star \star}$ & 0.17 & $1 \cdot 24^{\star}$ & $0 \cdot 10$ \\
\hline Meal-Ex & 1.05 & $0 \cdot 10$ & $1 \cdot 17$ & 0.11 & $1 \cdot 62^{\star \star}$ & 0.19 & 1.34 & 0.13 \\
\hline \multicolumn{9}{|l|}{ Insulin $(\mathrm{mU} / \mathrm{l}) \dagger$} \\
\hline CON & 6.63 & 0.89 & 30.41 & 6.08 & 41.68 & 6.47 & 30.85 & 4.76 \\
\hline Ex-Meal & $5 \cdot 24$ & 0.75 & $22 \cdot 16^{\star \star}$ & 4.26 & 36.43 & 5.56 & $25 \cdot 05^{\star \star}$ & 4.09 \\
\hline Meal-Ex & $6 \cdot 54$ & 0.93 & $18 \cdot 39^{* *}$ & 3.04 & $36 \cdot 14$ & $5 \cdot 30$ & $23 \cdot 61^{\star *}$ & 3.49 \\
\hline \multicolumn{9}{|l|}{ Glucose $(\mathrm{mmol} / \mathrm{l})$} \\
\hline CON & $5 \cdot 10$ & $0 \cdot 10$ & $5 \cdot 20$ & 0.17 & 5.52 & 0.17 & $5 \cdot 32$ & 0.14 \\
\hline Ex-Meal & $5 \cdot 29$ & 0.08 & $5 \cdot 36$ & 0.13 & 5.73 & 0.13 & $5 \cdot 50$ & 0.09 \\
\hline Meal-Ex & $5 \cdot 11$ & 0.12 & $5 \cdot 34$ & 0.09 & $5 \cdot 62$ & 0.18 & 5.43 & 0.13 \\
\hline
\end{tabular}

CON, control; Ex-Meal, exercise before breakfast; Meal-Ex, exercise after breakfast. Mean values were significantly different from the CON trial: ${ }^{\star} P<0.05 ;{ }^{\star \star} P<0.01$. $\dagger 1 \mathrm{mU} / \mathrm{l}=6.945 \mathrm{pmol} / \mathrm{l}$.

$(P<0.0001)$ at the end of the observation period when exercise was performed before, compared with after, breakfast, and only exercise performed before breakfast resulted in a significant attenuation in the postprandial TAG response over the entire observation period.

Relatively few studies have directly compared the effects of exercise timing relative to meal ingestion on macronutrient oxidation over the course of a day. The present findings are consistent with earlier work reporting that exercise performed before a morning meal resulted in a greater total amount of fat oxidised over a $2-8 \mathrm{~h}$ observation period compared with exercise performed after a meal ${ }^{(9,10)}$. The present data extend this work by showing that fat oxidation remained higher and fat balance was lower over the course of an $8.5 \mathrm{~h}$ observation period during which an ad libitum lunch was provided to replicate a typical 'real-life' setting. It is of interest that the difference in overall fat oxidation between the Ex-Meal and the Meal-Ex trials was entirely due to the difference in fat oxidation during the exercise session itself (Ex-Meal 23.0 (sem 1.3) g $v$. Meal-Ex 17.3 (sem 1.3) g, $P=0.0005$ ) rather than any differences in fat oxidation during the post-exercise period (Ex-Meal 53.0 (sem 3.8) g v. Meal-Ex 53.6 (SEm 2.5) g, $P=0.97)$. Thus, at least when exercise is of moderate intensity, the increased fat oxidation (and reciprocally lower carbohydrate oxidation), which occurs when exercise is performed in the fasted, compared with the fed state, does not appear to be offset by reduced fat and increased carbohydrate oxidation over the remainder of the day. This may reflect the fact that the greater carbohydrate oxidation during exercise in the Meal-Ex trial was likely to be due in large part to the increased oxidation of exogenous carbohydrate ingested at breakfast ${ }^{(33)}$, such that muscle and liver glycogen stores are unlikely to have been lower following the Meal-Ex trial compared with the Ex-Meal trial, despite the increased carbohydrate utilisation ${ }^{(33,34)}$, and it is low glycogen that stimulates the post-exercise increase in fat oxidation ${ }^{(35)}$. It is also worth noting that we did not observe any significant differences in fat oxidation in the post-exercise period between either exercise trial or the CON trial, although post-exercise fat oxidation values were numerically higher than the CON trial in both the Ex-Meal (by $3.4 \mathrm{~g}$ ) and Meal-Ex (by $4.0 \mathrm{~g}$ ) trials. While this observation is consistent with an earlier report from the authors, in which no significant increase in post-exercise fat oxidation was observed ${ }^{(4)}$, it contrasts with other studies that have reported significant increases in fat oxidation post-exercise ${ }^{(5,14,36)}$. It is therefore conceivable that the absence of a statistically significant increase in postexercise fat oxidation in either exercise trials, compared with the CON trial, could have been a consequence of low statistical power.

Despite the energy balance in both exercise trials being similar at the end of the $8.5 \mathrm{~h}$ observation period - both were approximately $2000 \mathrm{~kJ}$ lower than CON - the lower fat balance in the Ex-Meal trial compared with the Meal-Ex trial (approximately $1250 \mathrm{~kJ} v$. approximately $900 \mathrm{~kJ}$ lower than CON) could potentially have implications for the regulation of body fat. Loss of body fat requires a negative fat balance ${ }^{(1)}$, and thus if the effects seen in the present study persist over the longer term, greater fat loss would be expected to occur when exercise is performed in the fasted state before breakfast compared with after breakfast in the postprandial state. However, one important caveat to consider is that, as the present study was performed in a laboratory, rather than in a free-living setting, opportunity for spontaneous physical activity over the course of day was limited. Excluding exercise, the mean rate of energy expenditure over the $8.5 \mathrm{~h}$ observation period was approximately $1.2 \times$ RMR in all three trials. Under free-living conditions, the rate of energy expenditure would typically be expected to be in the order of $1.4-1.6 \times \mathrm{RMR}^{(37)}$. This would correspond to an increase in energy expenditure of approximately 500-1000 kJ over the period of observation in a free-living setting compared with 
the present laboratory-based setting. Thus, it is possible that differences over the day in spontaneous activity between the Meal-Ex- and Ex-Meal-type scenarios under free-living conditions could offset the differences in fat balance observed between the two exercise trials in the present laboratorybased study. Thus, a longer-term follow-up trial, under freeliving conditions, is warranted to determine whether the lower fat balance observed in the present trial, when the exercise was performed before, compared with after, eating breakfast, would translate to greater long-term fat loss.

Although many studies have examined the effects of shortterm exercise on meal consumption and appetite, research examining the potential interactive effects of exercise timing and appetitive behaviour is more limited. Three studies have suggested that exercise performed after, compared with before, a meal results in a greater suppressive effect of exercise $^{(38-40)}$. This contrasts with the present findings, where we report no difference in appetite responses between trials. However, only one of these earlier reports measured ad libitum food intake as well as subjective appetite scores $^{(38)}$. Interestingly, Deighton et al. ${ }^{(38)}$ reported that the greater suppression of appetite with postprandial exercise did not translate to a difference in ad libitum energy intake over a $24 \mathrm{~h}$ observation period, which is consistent with the energy intake data in the present study. We found that, overall, ad libitum energy intake was similar between all trials, indicating that, despite inducing an energy deficit of approximately $1800 \mathrm{~kJ}$, exercise, irrespective of its timing relative to meal ingestion, did not increase subsequent energy intake. This observation is consistent with previous findings that have typically shown that short-term energy intake (over $1-2 d$ ) is unaltered by an acute exercise-induced energy deficit ${ }^{(5,41,42)}$, which contrasts markedly with the marked increased energy intake observed in response to a dietary-induced energy deficit $^{(42)}$. An important caveat to consider in all laboratorybased investigations of energy intake is that the experimental setting itself may have influenced eating behaviour. We attempted to minimise this influence by avoiding investigator presence while the ad libitum lunch was consumed and by not informing participants that energy intake was being measured. However, it is possible that energy intake during the trials was not fully reflective of intake under free-living circumstances. In addition, a degree of caution is advised in extrapolating these short-term findings to potential effects on long-term weight and fat loss, as it has been suggested that, over the long-term, increases in energy intake can potentially explain the lower-than-expected weight loss often observed following exercise interventions ${ }^{(43,44)}$. This, however, is not an unequivocal finding, as other studies have reported that differences in energy intake do not explain the variability in the weight loss response to exercise interventions ${ }^{(45,46)}$.

The present study also highlights the effect of timing of exercise relative to meal ingestion on postprandial TAG responses. It is well-established that pre-meal exercise performed $4-18 \mathrm{~h}$ before a meal is effective in attenuating the lipaemic response to a fatty meal ${ }^{(5,14-17)}$. When exercise is of an aerobic endurance-based nature, the magnitude of the exercise-induced TAG lowering appears to be related to the energy expenditure/energy deficit incurred, largely independent of exercise intensity ${ }^{(11,14,47)}$. Interestingly, this relationship between energy expenditure and magnitude of TAG reduction does not appear to hold true when the exercise performed is of very high intensity, i.e. resistance ${ }^{(47)}$, or anaerobic sprinting-type ${ }^{(48)}$ in nature. However, the effect of exercise immediately prior to or immediately following a meal on postprandial TAG responses is less clear, with only two studies with conflicting findings directly comparing the effects of pre- and post-meal moderate-intensity exercise on postprandial TAG metabolism. Both Katsanos \& Moffat ${ }^{(18)}$ and Zhang et al. ${ }^{(19)}$ found that pre-meal exercise attenuated postprandial TAG concentrations, but only the former ${ }^{(18)}$ reported a similar effect for exercise performed in the postprandial state. Importantly, however, neither study considered the effects of exercise on the metabolic responses to subsequent meals, which is of key importance in translating laboratory findings to everyday living where sequential meals are consumed throughout the day. The present findings indicate that over the total $8.5 \mathrm{~h}$ observation period, which included an ad libitum lunch meal, exercise performed before breakfast significantly lowered the postprandial TAG response by $17 \%$, but the $11 \%$ reduction in the TAG response elicited by Meal-Ex did not achieve statistical significance.

However, when examining the data for the postprandial TAG response in separate intervals, we observed lower postprandial TAG in the post-lunch interval in both exercise conditions compared with the CON. This suggests that the smaller overall TAG reduction when exercise was performed after meal ingestion may have been a consequence of the exercise being performed at a later time point: in this trial, the exercise session began $2 \mathrm{~h}$ later than when exercise was performed prior to breakfast. This fits with data indicating that the increase in lipoprotein lipase (LPL) activity following exercise is delayed - increases in skeletal muscle LPL activity are evident $4 \mathrm{~h}$ post, but not immediately following, exercise $^{(49)}$. Thus, the time course for TAG lowering when exercise is performed at a later time may have been simply shifted to later in the day. However, effects of exercise on LPL may not tell the whole story, as reductions in TAG have been documented without concomitant increases in post-heparin plasma or skeletal muscle LPL activity ${ }^{(50,51)}$, implying that the reduction in TAG may be accounted for by mechanisms other than increased LPL activity. Recent data suggest that the TAG-lowering effect of exercise may be due to exerciseinduced changes in the composition of large VLDL particles to make them a better substrate for $\mathrm{LPL}^{(52)}$, but the time course for such changes is not currently known. It is, however, important to recognise that the TAG-lowering effect of exercise has been shown to last for at least $18-24 \mathrm{~h}^{(5,14-17)}$; hence, the effects seen in the present investigation would probably persist beyond the observation period until at least the following day in both exercise trials.

In contrast to the effects on TAG responses, both exercise sessions significantly reduced insulin responses over the overall $8.5 \mathrm{~h}$ observation period. In both trials, this effect was largely due to reductions in the insulin response in the 'breakfast-to-lunch' interval: insulin responses did not differ 
significantly between trials in the 'after lunch' period. Thus, in the present report, effects of exercise on TAG and insulin responses appeared to be dissociated, which is consistent with previous observations ${ }^{(53)}$, and the effects of exercise on the insulin response were transient, with the insulinlowering effect largely lost after ingestion of lunch. It is conceivable that the consumption of lunch may have diminished the insulin-reducing effect of exercise; recent studies have indicated that providing replacement energy after exercise, especially in the form of carbohydrate, can attenuate the insulin-sensitising effect ${ }^{(14,24,54)}$.

In conclusion, undertaking an exercise session, either before or after breakfast, resulted in more negative fat balance and lower postprandial insulin concentrations than a no-exercise CON trial over an $8.5 \mathrm{~h}$ observation period, which included an ad libitum lunch. However, exercise performed before breakfast resulted in a more negative fat balance than exercise performed after breakfast, and only the former significantly reduced postprandial TAG concentrations over the entire observation period. Thus, the present findings suggest that there may be an advantage for body fat regulation and lipid metabolism in exercising before compared with after breakfast. This has potential implications for recommendations of exercise timing relative to meal ingestion to maximise metabolic benefits. However, further study is needed to determine whether the results from the present short-term laboratory-based study extend over the long term under free-living conditions.

\section{Acknowledgements}

The authors have no conflicts of interest. N. M. F. F. was supported by the Universiti Kebangsaan Malaysia and the Ministry of Higher Education, Malaysia. Both authors contributed to the design of the study, data collection, data analysis and manuscript writing and revision.

\section{References}

1. Schutz Y (2004) Dietary fat, lipogenesis and energy balance. Physiol Behav 83, 557-564.

2. Hansen K, Shriver T \& Schoeller D (2005) The effects of exercise on the storage and oxidation of dietary fat. Sports Med 35, 363-373.

3. Jokisch E, Coletta A \& Raynor HA (2012) Acute energy compensation and macronutrient intake following exercise in active and inactive males who are normal weight. Appetite 58, $722-729$.

4. Burton FL, Malkova D, Caslake MJ, et al. (2010) Substrate metabolism, appetite and feeding behaviour under low and high energy turnover conditions in overweight women. Br J Nutr 104, 1249-1259.

5. Farah NM, Malkova D \& Gill JM (2010) Effects of exercise on postprandial responses to ad libitum feeding in overweight men. Med Sci Sports Exerc 42, 2015-2022.

6. Wu CL, Nicholas C, Williams C, et al. (2003) The influence of high-carbohydrate meals with different glycaemic indices on substrate utilisation during subsequent exercise. Br J Nutr 90, 1049-1056.
7. Horowitz JF, Mora-Rodriguez R, Byerley LO, et al. (1997) Lipolytic suppression following carbohydrate ingestion limits fat oxidation during exercise. Am J Physiol 273, E768-E775.

8. Dionne I, Van VS \& Tremblay A (1999) Postexercise macronutrient oxidation: a factor dependent on postexercise macronutrient intake. Am J Clin Nutr 69, 927-930.

9. Schneiter P, Di Vetta V, Jéquier E, et al. (1995) Effect of physical exercise on glycogen turnover and net substrate utilization according to the nutritional state. Am J Physiol 269, E1031-E1036.

10. Bennard P \& Doucet E (2006) Acute effects of exercise timing and breakfast meal glycemic index on exerciseinduced fat oxidation. Appl Physiol Nutr Metab 31, 502-511.

11. Malkova D \& Gill JMR (2006) Effects of exercise on postprandial lipoprotein metabolism. Future Lipidol 1, 743-755.

12. Cohn JS (1998) Postprandial lipemia: emerging evidence for atherogenicity of remnant lipoproteins. Can J Cardiol 14, 18B-27B.

13. Frayn KN (2002) Insulin resistance, impaired postprandial lipid metabolism and abdominal obesity. A deadly triad. Med Princ Pract 11, Suppl. 2, 31-40.

14. Burton FL, Malkova D, Caslake MJ, et al. (2008) Energy replacement attenuates the effects of prior moderate exercise on postprandial metabolism in overweight/obese men. Int J Obes (Lond) 32, 481-489.

15. Gill JMR, Al-Mamari A, Ferrell WR, et al. (2004) Effects of prior moderate exercise on postprandial metabolism and vascular function in lean and centrally obese men. $J \mathrm{Am}$ Coll Cardiol 44, 2375-2382.

16. Kolifa M, Petridou A \& Mougios V (2004) Effect of prior exercise on lipemia after a meal of moderate fat content. Eur J Clin Nutr 58, 1327-1335.

17. Miyashita M, Burns SF \& Stensel DJ (2008) Accumulating short bouts of brisk walking reduces postprandial plasma triacylglycerol concentrations and resting blood pressure in healthy young men. Am J Clin Nutr 88, 1225-1231.

18. Katsanos CS \& Moffatt RJ (2004) Acute effects of premeal versus postmeal exercise on postprandial hypertriglyceridemia. Clin J Sport Med 14, 33-39.

19. Zhang JQ, Thomas TR \& Ball SD (1998) Effect of exercise timing on postprandial lipemia and HDL cholesterol subfractions. J Appl Physiol 85, 1516-1522.

20. Hardman AE \& Aldred HE (1995) Walking during the postprandial period decreases alimentary lipaemia. J Cardiovasc Risk 2, 71-78.

21. Schlierf G, Dinsenbacher A, Kather H, et al. (1987) Mitigation of alimentary lipemia by postprandial exercise - phenomena and mechanisms. Metabolism 36, 726-730.

22. Klein L, Miller TD, Radam TE, et al. (1992) Acute physical exercise alters apolipoprotein E and C-III concentrations of apo E-rich very low density lipoprotein fraction. Atherosclerosis $97,37-51$.

23. Welle $S$ (1984) Metabolic responses to a meal during rest and low-intensity exercise. Am J Clin Nutr 40, 990-994.

24. Harrison M, O'Gorman DJ, McCaffrey N, et al. (2009) Influence of acute exercise with and without carbohydrate replacement on postprandial lipid metabolism. J Appl Physiol 106, 943-949.

25. Newsom SA, Schenk S, Thomas KM, et al. (2010) Energy deficit after exercise augments lipid mobilization but does not contribute to the exercise-induced increase in insulin sensitivity. J Appl Physiol 108, 554-560.

26. Stunkard AJ \& Messick S (1985) The three-factor eating questionnaire to measure dietary restraint, disinhibition and hunger. J Psychosom Res 29, 71-83. 
27. Van Strien T, Frijters JER, Bergers APA, et al. (1986) Dutch eating behavior questionnaire for assessment of restrained, emotional, and external eating behavior. Int J Eat Disord $\mathbf{5}, 315$.

28. Frayn KN \& Macdonald IA (1997) Assessment of substrate and energy metabolism in vivo. In Clinical Research in Diabetes and Obesity Part I: Methods, Assessment, and Metabolic Regulation, pp. 101-124 [B Draznin and R Rizza, editors]. Totowa, NJ: Humana Press.

29. Flint A, Raben A, Blundell JE, et al. (2000) Reproducibility, power and validity of visual analogue scales in assessment of appetite sensations in single test meal studies. Int J Obes Relat Metab Disord 24, 38-48.

30. Department for Environment FaRA (2004) Estimates of Food Consumption and Energy and Nutrition Intakes in the UK in 2002-2003. London: HMSO

31. Herman CP \& Polivy J (2005) Normative influences on food intake. Physiol Behav 86, 762-772.

32. Gill JM, Malkova D \& Hardman AE (2005) Reproducibility of an oral fat tolerance test is influenced by phase of menstrual cycle. Horm Metab Res 37, 336-341.

33. Tsintzas K \& Williams C (1998) Human muscle glycogen metabolism during exercise. Effect of carbohydrate supplementation. Sports Med 25, 7-23.

34. Coyle EF, Coggan AR, Hemmert MK, et al. (1985) Substrate usage during prolonged exercise following a preexercise meal. J Appl Physiol 59, 429-433.

35. Kiens B \& Richter EA (1998) Utilization of skeletal muscle triacylglycerol during postexercise recovery in humans. Am J Physiol 275, E332-E337.

36. Charlot K, Pichon A \& Chapelot D (2011) Exercise prior to a freely requested meal modifies pre and postprandial glucose profile, substrate oxidation and sympathovagal balance. Nutr Metab (Lond) 8, 66.

37. FAO/WHO/UNU (1985) Energy and Protein Requirements. Report of a Joint FAO/WHO/UNU Expert Consultation no. 724. Geneva: WHO.

38. Deighton K, Zahra JC \& Stensel DJ (2012) Appetite, energy intake and resting metabolic responses to $60 \mathrm{~min}$ treadmill running performed in a fasted versus a postprandial state. Appetite 58, 946-954.

39. Cheng MH, Bushnell D, Cannon DT, et al. (2009) Appetite regulation via exercise prior or subsequent to high-fat meal consumption. Appetite 52, 193-198.

40. Borer KT, Wuorinen E, Chao C, et al. (2005) Exercise energy expenditure is not consciously detected due to oro-gastric, not metabolic, basis of hunger sensation. Appetite 45, $177-181$.
41. Hopkins M, King NA \& Blundell JE (2010) Acute and longterm effects of exercise on appetite control: is there any benefit for weight control? Curr Opin Clin Nutr Metab Care 13, 635-640.

42. King JA, Wasse LK, Ewens J, et al. (2011) Differential acylated ghrelin, peptide YY3-36, appetite, and food intake responses to equivalent energy deficits created by exercise and food restriction. J Clin Endocrinol Metab 96, 1114-1121.

43. King NA, Hopkins M, Caudwell P, et al. (2008) Individual variability following 12 weeks of supervised exercise: identification and characterization of compensation for exercise-induced weight loss. Int J Obes (Lond) 32, 177-184.

44. Turner JE, Markovitch D, Betts JA, et al. (2010) Nonprescribed physical activity energy expenditure is maintained with structured exercise and implicates a compensatory increase in energy intake. Am J Clin Nutr 92, 1009-1016.

45. Barwell ND, Malkova D, Leggate M, et al. (2009) Individual responsiveness to exercise-induced fat loss is associated with change in resting substrate utilization. Metabolism 58, $1320-1328$.

46. Manthou E, Gill JM, Wright A, et al. (2010) Behavioral compensatory adjustments to exercise training in overweight women. Med Sci Sports Exerc 42, 1121-1128.

47. Peddie MC, Rehrer NJ \& Perry TL (2012) Physical activity and postprandial lipidemia: are energy expenditure and lipoprotein lipase activity the real modulators of the positive effect? Prog Lipid Res 51, 11-22.

48. Gabriel B, Ratkevicius A, Gray P, et al. (2012) High-intensity exercise attenuates postprandial lipaemia and markers of oxidative stress. Clin Sci (Lond) 123, 313-321.

49. Kiens B, Lithell H, Mikines KJ, et al. (1989) Effects of insulin and exercise on muscle lipoprotein lipase activity in man and its relation to insulin action. J Clin Invest 84, 1124-1129.

50. Herd SL, Kiens B, Boobis LH, et al. (2001) Moderate exercise, postprandial lipemia and skeletal muscle lipoprotein lipase activity. Metabolism 50, 756-762.

51. Ferguson MA, Alderson NL, Trost SG, et al. (1998) Effects of four different single exercise sessions on lipids, lipoproteins, and lipoprotein lipase. J Appl Physiol 85, 1169-1174.

52. Al-Shayji IA, Caslake MJ \& Gill JM (2012) Effects of moderate exercise on $\mathrm{VLDL}_{1}$ and intralipid kinetics in overweight/ obese middle-aged men. Am J Physiol Endocrinol Metab 302, E349-E355.

53. Gill JMR, Herd SL, Tsetsonis NV, et al. (2002) Are the reductions in triglyceride and insulin levels after exercise related? Clin Sci 102, 223-231.

54. Holtz KA, Stephens BR, Sharoff CG, et al. (2008) The effect of carbohydrate availability following exercise on wholebody insulin action. Appl Physiol Nutr Metab 33, 946-956. 